A further challenge of 5-fluorouracil was not felt to be appropriate since the symptoms were very unpleasant, and we felt that they could be attributed to the presence of the drug in the tear film. A direct correlation has been shown between the amount of lacrimation and the concentration of fluorouracil in the tears. ${ }^{6}$ Side effects due to ocular surface toxicity are well documented and include blurred vision, excessive lacrimation, irritative conjunctivitis, keratitis, blepharitis, cicatricial ectropion, and punctal stenosis. ${ }^{1457} \mathrm{We}$ thought it was of interest to record this new presentation which proved reversible upon discontinuing the 5-fluorouracil therapy.

J E FORBES

D J BRAZIER

Department of Ophthalmology, University College Hospital, London

M SPITTLE Department of Oncology, The Middlesex Hospital,

London

1 Hammersly J, Luce JK, Florenz TR, et al. Excessive lacrimation from fluorouracil treatment. FAMA 1973; 225: 747-8.

2 Bonadonna G, Brusamolino E, Pennucia V, et al. Combination chemotherapy as an adjuvant treatment in operable breast cancer. NEnglF Med 1976; 294: 405-10.

3 Brown N, Bron AJ. Recurrent erosion of the cornea. Brf Ophthalmol 1976; 66: 84-96.

4 Haidak DJ, Hurwitz BS, Yeung KY. Tear-duct fibrosis (dacryostenosis) due to 5-fluorouracil. Ann Intern Med 1978; 88: 657.

5 Insler MS, Helm CJ. Ankyloblepharon associated with systemic 5-fluorouracil treatment. Ann Ophthalmol 1987; 19: 374-5.

6 Christophides N, Vajda FJE, Lucas I, Louis WJ. Ocular side effects with 5-fluorouracil. Aust NZ Y Med 1979; 9: 143-4.

7 Caravella LP, Burns JA, Zangmeister M. Punctal-canalicular stenosis related to systemic fluorouracil therapy. Arch Ophthalmol 1981; 99: 284-6.

\section{Fractured laser fibreoptic cord}

EDIToR,-The report by Bloom et al ${ }^{1}$ on lenticular burns following argon panretinal photocoagulation is interesting. This article highlights an unusual complication of posterior segment laser surgery. The source of the problem was the fibreoptic cord. We would like to emphasise the importance of maintenance of fibreoptic cords.

Our department now uses a double frequency YAG 'crystal focus emerald' laser (Biovision, Park Center, Walnut Creek, CA, USA) which produces monochromatic green light of $532 \mathrm{~nm}$ for posterior segment laser surgery. This solid state photocoagulator incorporates a helium neon system to allow visualisation of the aiming beam. Several authorised laser users complained that the aiming beam could not be seen as before and was only visualised after certain modifications were made including decreasing the overall illumination and using a red free filter; however, this led to poor resolution of retinal details. It was also noted that an increased power level was required to obtain the same retinal response. Peripheral photocoagulation became extremely difficult and treatment of all patients requiring macular laser treatment had to be postponed.

The manufacturers of the laser were asked to inspect the system and it was found that the fibreoptic cord was kinked and damaged at its entry to the microscope housing. Replacement of the cord and securing it in a better position led to resolution of the initial problem. Fortunately there were no documented complications, but some patients did have to be relisted for their laser treatment in an already busy department.

We would recommend in accordance with Bloom et al that, apart from routine maintenance of laser systems, the fibreoptic cord must be protected at all times from even minimal injury.

J SINGH
K SWA
Princess Alexandra Eye Pavilion,
Chalmers Street,
Edinburgh EH3 9HA

Bloom SM, Mahl CF, Schiller SB. Lenticular burns following argon panretinal photocoagulation. Br f Ophthalmol 1992; 76: 630-1.

\section{Reply}

EDIToR,-The comments by Drs Singh and Swa underscore the necessity of protecting the laser fibreoptic cord from injury at all times.

We have also been using the crystal focus emerald laser (Biovision, Walnut Creek, CA, USA) for several years without fibreoptic damage. This laser employs a portable, removable delivery system that attaches to a variety of slitlamps. We have left this attachment permanently secured to the slit-lamp in our laser suite, thereby minimising risk of fibreoptic damage.

$$
\begin{array}{r}
\text { S M BLOOM } \\
\text { CF MAHL } \\
\text { S B SCHILLER } \\
\\
\text { Indiana Retina Associates, } \\
\text { Scott Memorial Hospital, } \\
\text { Highway } 31 \text { North, } \\
\text { Scottsburg, } \\
\text { IN 47170, USA }
\end{array}
$$

\section{Iris crystals and uveitis}

EDITOR, -I read with interest the report by Lam et al ${ }^{\prime}$ describing three patients with iris crystals in chronic iridocyclitis. I would like to add another case to the literature.

A 15-year-old Asian girl presented in November 1990 with gradual, painless reduction of vision in both eyes over the previous 2 years. Examination revealed a visual acuity of $6 / 9$ in each eye with a low myopic correction. She had bilateral panuveitis, early posterior subcapsular lens opacities, mild diffuse retinal vasculitis with inferior vitreous snowballs but no frank snowbanking. The right iris stroma showed multiple, tiny, refractile crystalline deposits. A few pupillary iris (Koeppe) nodules were noted in each eye and a number of small follicles were seen in the inferior conjunctival fornices. She was treated with topical steroids only and thoroughly investigated. The only abnormalities detected were a slightly raised serum $\operatorname{IgE}$ and an iron deficiency anaemia. Biopsy of the conjunctival follicles showed chronic inflammatory change only. In June 1991, her vision dropped to 6/18 right and 6/24 left due to macular oedema. She underwent a short course of systemic steroids with rapid improvement in vision. When she was last reviewed in February 1993 her vision was 6/24 right, $6 / 9$ left; the cause for the reduced right vision being a combination of lens and vitreous opacities. Interestingly, apart from at presentation, the iris crystals were not seen again until her visits in November 1992 and February 1993. At no time were crystals seen on the left iris.
It is likely that she may require right cataract extraction in the near future, which will allow detailed analysis to be performed on this unusual physical sign.

PHILIP I MURRAY University of Birmingham, Deparivent of Ophthalmology, Birmingham and Midland Eye Hospital, Birmingham B3 $2 N S$

1 Lam S, Tessler HH, Winchester $\mathrm{K}$, van Hecke $\mathrm{H}$, Lam BL. Iris crystals in chronic iridocyclitis. Brf Ophthalmol 1993; 77 : 181-2.

\section{Reply}

EDIToR, - We would like to thank P I Murray for reporting another case of iris crystals. As in previous reports, this case showed that iris crystals are associated with chronic uveitis, could be unilateral, and may transiently disappear. ${ }^{12}$ However, this case has some unique features. To our knowledge, this is the only case of iris crystals that occurred in a patient with chronic panuveitis (the previously reported cases occurred in patients with chronic iridocyclitis). Furthermore, the elevation of serum IgE levels is also intriguing, since hypergammaglobulinaemia has been documented in some of the cases of iris crystals.

We believe that iris crystals occur more commonly than is reported. Further studies and case reports will be needed to elucidate the pathogenesis of iris crystals.

$$
\begin{array}{r}
\text { SLAM } \\
\text { H H TESSLER } \\
\text { K WINCHESTER } \\
\text { H VAN HECKE } \\
\text { B L LAM } \\
\text { University of Illinois at Chicago, } \\
\text { UIC Eye Center (M/C 648), } \\
\text { Department of Ophthalmology, } \\
\text { Eye and Ear Infirmary, } \\
\text { 1855 West Taylor Street, } \\
\text { Chicago, Illinois 60612, USA }
\end{array}
$$

1 Lam S, Tessler HH. Iris crystals and hypergammaglobulinemia. Am $\mathcal{f}$ Ophthalmol 1990 110: 440-1.

2 Lam S, Tessler HH, Winchester K, van Hecke H, Lam BL. Iris crystals in chronic iridocyclitis. Brf Ophthalmol 1993; 77: 181-2.

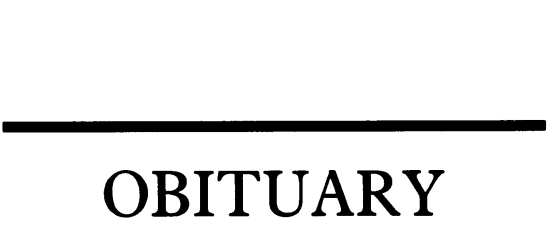

\section{T A CASEY}

Thomas Aquinas Casey, director of the corneoplastic unit at East Grinstead and consultant at Hillingdon Hospital, died on 25 February 1993 , from a rapidly progressive lung cancer, at 6 the age of 63.

After qualifying in Dublin, and nearly 10 years at Westminster Hospital as ophthalmic registrar, Tom was appointed to direct the corneoplastic unit on the sudden death of its founder, Sir Benjamin Rycroft. There he established an impressive postgraduate centre for teaching and research, including a three day international corneoplastic congress in 1977. At an early stage he had pioneered a technique for deep freezing corneas (which permitted the establishment of a bank of tissue typed donor material), and other innovations in corneal surgery, such as the use of recombinant epidermal growth factor. This innovative activity was accompanied by copious publications, of which the latest, a prize winning atlas of corneal dystrophies, came out only a year ago. 